\title{
New Evidence on the Determinants of Absenteeism Using Linked Employer-Employee Data
}

\section{by Georges DIONNE and Benoit DOSTIE}

\section{Cahier de recherche $n^{0}$ IEA-05-04}

JUNE 2005

ISSN : 0825-864

Copyright (C) 2005. Benoit Dostie, Institut d'économie appliquée et Georges Dionne, Chaire de recherche du Canada en gestion des risques.

Tous droits réservés pour tous pays. Toute traduction ou toute reproduction sous quelque forme que ce soit est interdite.

Les textes publiés dans la série des Cahiers de recherche HEC n'engagent que la responsabilité de leurs auteurs.

La publication de ce Cahier de recherche a été rendue possible grâce à des subventions d'aide à la publication et à la diffusion de la recherche provenant des fonds de HEC Montréal.

Direction de la recherche, HEC Montréal, 3000, chemin de la Côte-Sainte-Catherine, Montréal (Québec) Canada H3T 2 A7. 


\title{
New Evidence on the Determinants of Absenteeism Using Linked Employer-Employee Data*
}

\author{
Georges Dionne ${ }^{\dagger}$ and Benoit Dostie ${ }^{\ddagger}$
}

June 13th 2005

\begin{abstract}
In this paper, we provide new evidence on the determinants of absenteeism using the Workplace Employee Survey (WES) 1999-2002 from Statistics Canada. Our paper extends the typical labour-leisure model used to analyze the decision to skip work to include firm-level policy variables relevant to the absenteeism decision and uncertainty about the cost of absenteeism. It also provides a non-linear econometric model that explicitly takes into account the count nature of absenteeism data and unobserved heterogeneity at both the individual and firm level. Controlling for very detailed demographic, job and firm characteristics (including workplace practices), we find that dissatisfaction with contracted hours is a significant determinant of absence.

KEY WORDS: Absenteeism; Linked Employer-Employee Data; Unobserved Heterogeneity; Count Data Models.
\end{abstract}

\section{Introduction}

In this paper, we provide new evidence on the determinants of absenteeism using linked employer-employee data. It has long been recognized that while

*The authors are grateful to seminar participants at the "Journées du CIRPÉE (Knowlton, Québec)", SCSE (Manoir Richelieu, Québec), CEA (Hamilton, Ontario), and SOLE (San Francisco) and in particular to Pierre Fortin, Pierre Lefebvre, Cindy Carter and Kathryn Shaw. Rob Clark also provided very helpful comments. The usual caveat applies.

${ }^{\dagger}$ Canada Research Chair in Risk Management, HEC Montréal, CREF, and CIRPÉE.

${ }^{\ddagger}$ Corresponding author: Institute of Applied Economics, HEC Montréal, 3000, chemin de la Côte-Sainte-Catherine, Montréal, H3T 2A7. Phone: 514-340-6453; Fax: 514-340-6469; Email: benoit.dostie@hec.ca, CREF, and CIRPÉE 
the decision to skip work is made by the individual, reasons for doing so might also be related to personnel considerations or the organizational structure of the firm (Frankel (1921)). Linked data thus provides a unique opportunity to disentangle conflicting causes of absenteeism.

Despite its rising frequency and associated cost, there are relatively few studies on the determinants of absenteeism. Moreover, it could be argued that most of the existing studies on the determinants of absenteeism suffer from the use of less than adequate data. A first strand of the literature focuses on only one kind of absenteeism, namely absenteeism due (officially) to health reasons. These studies generally use data from a health insurance company or government agency. ${ }^{1}$ A second strand of the literature uses detailed absenteeism data from one company or a very small sample of firms ${ }^{2}$. It is not clear that their results are generalizable outside their small samples. ${ }^{3},{ }^{4}, 5$

Our work is thus more closely related to the second strand of the literature using employee level data. However, we examine the determinants of absenteeism using survey data, the Workplace Employee Survey (WES) 1999-2002 from Statistics Canada. The use of WES has numerous advantages for the study of the determinants of absenteeism: (1) the survey is designed to be represen-

\footnotetext{
${ }^{1}$ For example, Henrekson and Persson (2004) use aggregate data from the National Social Insurance Board of Sweden, Johansson and Palme (2002) use data from the 1991 Swedish Level of Living Survey (SLLS). In the U.S., Vistnes (1997) uses the 1987 National Medical Expenditure Survey.

${ }^{2}$ Kauermann and Ortlieb (2004) have absenteeism data from one German firm. Barmby (2002) also has data on only one UK manufacturing firm. Delgado and Kiesner (1997) focus on London buses operators. Drago and Wooden (1992) work on a sample of 15 firms from the U.S., Canada and New-Zealand. Barmby, Orme, and Treble (1991) use data on four factories of an unidentified firm. Wilson and Peel (1991) have data on a sample of 52 firms in the engineering and metal industry in the United Kingdom. Dunn and Youngblood (1986) use 1977 data from one utility company.

${ }^{3}$ A notable exception is Allen (1981) who uses the 1972-73 Quality of Employment Survey. However, this survey does not have any information about the employer and therefore cannot be used to study the link between workplace practices and absenteeism.

${ }^{4}$ Other papers focusing on absenteeism include Gilleskie (1998) who focuses on the absenteeism decision of individuals with acute illnesses, Ehrenberg (1970) who studies the link between absenteeism and the decision of the firm to use overtime, and Allen (1983) who estimates the cost of absenteeism.

${ }^{5}$ A third strand takes a more macroeconomic approach. For example, Kenyon and Dawkins (1989) use aggregate Australian time-series data.
} 
tative of the whole universe of firm operating in Canada; (2) in each sampled firm, a subset of workers from the firm was sampled so that the survey is also representative of the universe of workers in $\mathrm{Canada}^{6} ;(3)$ since the survey is linked, we have detailed micro data on each of these workers, including days of absenteeism during the year, demographic and job characteristics, preferences and human capital variables (this is in addition to the usual firm-level characteristics); (4) each worker was asked to recall the number of days absent from work in the past year; (5) the linked nature of the data allows us to take into account firm unobserved heterogeneity; (6) and the longitudinal nature of the data allows us to take into account worker unobserved heterogeneity.

We start first by extending the typical labor-leisure model used to analyze the decision to skip work to include firm-level policy variables relevant to the absenteeism decision and uncertainty about the cost of absenteeism to the worker. We next describe an econometric model that explicitly takes into account the count data nature of absenteeism data and also incorporates unobserved heterogeneity at both the individual and firm level. Data sources and variable descriptions are presented in Section 4. We describe the results in section 5 and briefly conclude in the final section.

\section{Theoretical Framework}

We use the typical labor-leisure choice model to study the absenteeism decision (see Allen (1981), Allen (1983), Barmby, Orme, and Treble (1991), Delgado and Kiesner (1997) and Dunn and Youngblood (1986)) $)^{7}$. We assume that each job offers a work schedule as well as a wage rate. Since search is costly, a worker may accept a job offer even though at the contracted number of work hours $\left(t^{c}\right)$

\footnotetext{
${ }^{6}$ Abowd and Kramarz (1999) classify WES as a survey in which both the sample of workplaces and the sample of workers are cross-sectionally representative of the target population.

${ }^{7}$ The following discussion is also drawn from Vistnes (1997) and Johansson and Palme (1996). See Hausman (1980) and Blomquist (1983) for the foundations of the basic model.
} 
his marginal rate of substitution between leisure and income does not equal the wage rate $(w)$. When a worker contracts for more than his desired hours given $w$, he retains an incentive to consume more leisure. One way of doing so is to be absent from work. In this theoretical framework, an emphasis will be placed on the explicit random cost of such a decision and on how the firms and jobs characteristics affect this decision. These two aspects will become important in the empirical part of the paper and have not been addressed in the literature.

Absenteeism results in lost output when the absent worker is replaced by someone who is generally less efficient or is not replaced at all. For the employment relation to continue, the firm must be compensated for this loss. In addition to losing earnings he would have received if he had reported, the worker faces a penalty $(D)$ for each scheduled work period missed. In practice, this penalty will be observed in the form of a decreased probability of receiving a promotion or merit wage increase and an increased likelihood of being dismissed. Denoting time absent form work as $t^{a}$, one can then write

$$
D=D\left(t^{a}\right) \quad D^{\prime} \geq 0, \quad D^{\prime \prime} \geq 0, \quad D(0)=0
$$

The workers who miss the most days pay the largest penalties. The costs of increased amounts of absenteeism to the firm are presumed to be non-decreasing, yielding a constant or graduated penalty structure. Workers with perfect attendance records are not penalized at all. Since the worker does not really know this potential cost when he makes his decision, we consider the possibility that $D\left(t^{a}\right)$ can be a random variable. So, we write $\widetilde{D}\left(t^{a}\right)$ when this is the case.

Holding work schedule flexibility constant, the work attendance decision can be analyzed within the traditional labor-leisure choice framework. Workers maximize an expected utility function containing consumption $(C)$ and leisure 
time $(L)$ as its arguments ${ }^{8}$

$$
E U=E U(C, L ; P, F) .
$$

The expected utility of the worker is also a function of a vector of personal characteristics $(P)$ and a vector of firm characteristics $(F)$. Letting $R$ equal the individual non-labor income, the budget constraint of the worker is

$$
R+w\left(t^{c}-\left(1-s_{L}\right) t^{a}\right)-\widetilde{D}\left(t^{a}\right)=C
$$

where the price of the consumption good $C$ is normalized to one and $s_{L}$ is a variable that takes the value of one if a worker has full sick leave benefits ${ }^{9}$ and less than one otherwise. Workers also face a time constraint of

$$
t-t^{c}-t^{a}-t^{l}=0
$$

where $t$ represents the total amount of time in the period under consideration and $t^{l}$ is leisure hours. So we can write $t^{a}+t^{l}=L$. Substitution of (2) and (3) in (1) and differentiation of the latter with respect to $t^{a}$ produces the first-order condition

$$
E\left[U_{L}-\left(w\left(1-s_{L}\right)+\widetilde{D}^{\prime}\left(t^{a}\right)\right) U_{C}\right]=0
$$

where $U_{k}>0$ indicates the partial derivative of $U$ with respect to $k=L, C$. The variable $\widetilde{D}\left(t^{a}\right)$ can be expressed more directly by defining $w^{a}$ as the cost of being absent. So we can write $\widetilde{D}\left(t^{a}\right)=w^{a} t^{a}$ and, as already mentioned, $w^{a}$

\footnotetext{
${ }^{8}$ See Dionne and Eeckhoudt (1987) for such a theoretical framework.

${ }^{9}$ We use the same hypothesis as Vistnes (1997) of modelling $s_{L}$ as a binary variable due to data limitations. As in Vistnes (1997), detailed information on sick leave provisions, such as the stock of sick leave, carry-over provisions, whether sick leave benefits pay the worker fully or partially, and wheter the sick leave can be applied toward early retirement or used for maternity leave, is not available. Detailed job characteristics in the empirical analysis may serve as proxies for these provisions.
} 
can be a random variable when the decision on $t^{a}$ is made. In this case, the first order condition (4) becomes

$$
E\left[U_{L}-\left(w\left(1-s_{L}\right)+w^{a}\right) U_{C}\right]=0 .
$$

A worker will be absent on any given day as long as the extra leisure is more valuable to him than the sum of the wages he would have earned that day and the resulting loss in future earnings. This means that the shadow price of time for absent workers is greater than the contracted wage.

By differentiating the first-order conditions for $s_{L}=0$ and applying Cramer's Rule, one can show, under the usual conditions of an upward sloping labor supply curve, that

$$
\frac{\partial t^{a}}{\partial w}<0, \frac{\partial t^{a}}{\partial R}>0, \frac{\partial t^{a}}{\partial t^{c}}>0, \frac{\partial t^{a}}{\partial R i s k}<0, \frac{\partial t^{a}}{E\left(w^{a}\right)}<0 .
$$

where Risk is a measure of the risk associated to $w^{a}$ and $E\left(w^{a}\right)$ its mean. See Dionne and Eeckhoudt (1987) for a sufficient condition yielding $d t^{a} / d R i s k<0$. (Details for the derivation of results in (6) are in Appendix).

The effect of a change in the wage rate on time absent from work is ambiguous a priori because income and substitution effects operate in opposite directions. However, under the conditions of an upward sloping labor supply curve, a negative sign is obtained when $s_{L}=0$ or is sufficiently small. An increase in non-labor income leads to more demand for all non-inferior goods and services, including time absent from work. If the number of contracted hours changes, the number of absences move in the same direction. Increased penalties for absenteeism reduce the number of days missed; as does an increased risk of penalty.

In cases where full sick leave is available, the product of $w$ and $t^{a}$ disappears 
from (2) and the first-order equilibrium condition becomes

$$
E\left[U_{L}-w^{a} U_{C}\right]=0 .
$$

Unless the penalty function is made steeper, an individual will be absent more frequently in plants where sick leave is fully paid to absent workers. It should be noted that the effect of a wage change on the likelihood of absence is unambiguously positive in this case because there is no longer a substitution effect.

Denoting the scheduling flexibility permitted by one's employer as $f$ (we expect $\left.\partial t^{A} / \partial f<0\right)$, the model can be summarized as

$$
\begin{array}{rcccccc}
t^{A}=t^{A}( & w, & R, & t^{c}, & E\left(w^{a}\right), & \text { Risk, } & f) . \\
(-) & (+) & (+) & (-) & (-) & (-)
\end{array}
$$

We provide a structural form for these relationships in the next section.

\section{Empirical Specification}

From the above behavioral model, we can derive a structural econometric model of the absenteeism decision. Extending the model of Hausman (1980) and Blomquist (1983) proposed for labor force participation, we can write the following functional form for the utility function:

$$
U\left(C, t^{a}+t^{l} ; P, F\right)=\exp \left\{-\left(1+\frac{\beta(C+\bar{P}+\bar{F})}{b-t+\left(t^{a}+t^{l}\right)}\right)\right\}\left(\frac{t-\left(t^{a}+t^{l}\right)-b}{\beta}\right)
$$

where

$$
\bar{P}=P / \beta-\alpha / \beta^{2}, \bar{F}=F / \beta-\alpha / \beta^{2}, \quad b=\alpha / \beta,
$$


$\alpha$ and $\beta$ are parameters and absolute risk aversion is assumed equal to one ${ }^{10}$. From this utility function, one can verify that the first order condition yields

$$
t^{a}=t^{c}-\alpha\left(w\left(1-s_{L}\right)+E\left(w^{a}\right)+1 / 2 \sigma^{2}\right)-\beta\left(R+t^{c} w s_{L}\right)-\gamma P-\eta F
$$

assuming normal distribution for $w^{a}$, which yields $\sigma^{2}$ as the measure of risk. In a more compact form, (10) can be rewritten as

$$
t^{a}=t^{c}-\alpha w^{*}-\beta R^{*}-\gamma P-\eta F
$$

where $w^{*}$ can be interpreted as the relative cost of being absent and $R^{*}$ as the virtual benefit or income related to absence. A positive $\alpha$ parameter and a negative $\beta$ parameter are expected.

In this simple model, when preferences are not random, days of absenteeism can be represented by a Poisson process (see Hausman, Hall, and Griliches (1984); Gouriéroux, Monfort, and Trognon (1984)). In fact, since absences are recorded as non-negative integers, modeling such data with a continuous distribution could lead to inconsistent parameter estimates. Let $t_{i j t}^{a}$ be the observed number of days of absenteeism for employee $i$ in firm $j$ at time $t$. The basic model is

$$
P\left(t_{i j t}^{a} \mid \lambda_{i j t}\right)=\frac{e^{-\lambda_{i j t}}\left(\lambda_{i j t}\right)^{t_{i j t}^{a}}}{t_{i j t}^{a} !}
$$

with

$$
\lambda_{i j t}=t_{i j t}^{c}-\alpha w_{i j t}^{*}-\beta R_{i j t}^{*}-\gamma P_{i t}-\eta F_{j t}>0
$$

It should be repeated that $t_{i j t}^{c}$ (contracted hours) are exogenous in the model. This decision variable is already fixed when the worker (or nature) makes a decision about $t^{a}$.

\footnotetext{
${ }^{10}$ See Johansson and Palme (1996), for a similar model where the firms variables are not considered and $w^{a}$ is not present in the budget constraint.
} 
It is typical to introduce unobserved heterogeneity in the Poisson model in a multiplicative form through $\lambda_{i j t}$. Unobserved heterogeneity should be present because many non observable factors in the data set can affect the sensitivity to economic incentives related to work absence decisions. We use the following parameterization for $\lambda_{i j t}$

$$
\lambda_{i j t}=\exp \left(\delta_{i j}+\psi_{j}+\theta_{i j}\right)
$$

where

$$
\delta_{i j}=t_{i j t}^{c}-\alpha w_{i j t}^{*}-\beta R_{i j t}^{*}-\gamma P_{i t}-\eta F_{j t}
$$

The additional parameter $\psi_{j}$ captures unobservable factors of the firm orthogonal to other observed firm characteristics. We assume firm unobserved heterogeneity to be normally distributed with mean zero. The variance of $\psi_{j}\left(\sigma_{\psi}\right)$ is identified by the observation of many workers coming from the same firm.

Since we do not observe worker mobility due to the design of the survey, we do not include pure worker unobserved heterogeneity but because of the longitudinal nature of the data, we have repeated observations on the employeremployee relationship which allows us to take into account unobserved job heterogeneity $\left(\theta_{i j}\right)$. We also assume that $\theta_{i j}$ is distributed normally with variance $\sigma_{\theta}$ and is orthogonal to $\psi_{j}{ }^{11}$. Firm unobserved heterogeneity might proxy for the cost of absence to the firm when observed heterogeneity is not sufficiently informative. For example, the cost of absence to the firm might be pretty low if substitute workers are easily available and are as productive as regular workers (Allen (1983)) and therefore, the econometrician might observe higher absenteeism than in an otherwise identical firm where such substitute workers are not available. From a statistical point of view, it is necessary to take into account

\footnotetext{
${ }^{11}$ Note that this specification is not subject to the usual objections to the Poisson model since the inclusion of firm and worker unobserved heterogeneity allows for dispersion at both the worker and firm level.
} 
both sources of heterogeneity in order to avoid the problem of spurious regressions due to multiple observations on the same worker over time and the same firm characteristics over its employees.

The joint likelihood is obtained by numerically integrating out the heterogeneity components from the product of the conditional likelihoods of the firms, assuming joint normality of the heterogeneity components. Since a closed form solution to the integral does not exist, the likelihood was computed by approximating the normal integral by a weighted sum over "conditional likelihoods", i.e. likelihoods conditional on certain well-chosen values of the residual.

\section{Data}

We use data from the Workplace and Employee Survey (WES) 1999-2002 conducted by Statistics Canada. The survey is both longitudinal and linked in that it documents the characteristics of the workers and of the workplaces over time. The target population for the "workplace" component of the survey is defined as the collection of all Canadian establishments who paid employees in March of the year of the survey. The survey, however, does not cover the Yukon, the Northwest territories and Nunavut. Establishments operating in fisheries, agriculture and cattle farming are also excluded. For the "employee" component, the target population is the collection of all employees working, or on paid leave, in the workplace target population.

The sample for the workplaces comes from the "Business registry" of Statistics Canada which contains information on every business operating in Canada. Employees are then sampled from an employees list provided by the selected workplaces. For every workplace, a maximum of twelve employees are selected, and for establishments with less than four employees, all employees are sampled. In the case of total non-response, respondents are withdrawn entirely from the 
survey and sampling weights are recalculated in order to preserve representativeness of the sample. WES selects new employees and workplaces in odd years (at every third year for employees and at every fifth year for workplaces). We used the final sampling weights for employees as recommended by Statistics Canada in all our regressions.

We finally exclude establishments with less than ten employees from the sample because survey questions on work practices were not intended for them. Individuals who did no work throughout the year are also included but we control for their limited exposure to the risk of being absent in our regression framework. The rich structure of the data set allows us to control for a variety of factors determining absenteeism decisions. From the worker questionnaire, we are able to extract detailed demographic characteristics including measures of health, human capital, job satisfaction and income from other sources. Moreover, we use detailed explanatory variables on the employment contract including wage, contracted hours and information about working hours flexibility and when these working hours take place.

From the firm questionnaire, we are able to construct firm size indicators and build measures of turnover and vacancy rates. Even more important, the establishment questionnaire includes very detailed information about changes in organizational practices (15 indicators) and current workplace practices (6). We complement those by adding some indicators for the type of nonwage benefits that the firm offers to its workers. Finally, our regressions include industry (13), occupation (6) and time (4) dummies. Summary statistics on all explanatory variables are presented in Table 1 for the dependent variable, Table 2 for the employees and Table 3 for the employer. Note that week absent in Table 1 refers to a five day workweek. Thus zero means the worker was absent strictly less than five days. 


\section{Results}

Complete estimation results are presented in the multiple parts of Table 4 . The first column presents results from the estimation of the standard Poisson model from equation (12) and column "IRR" shows the corresponding incidence rate ratios. The two next columns show estimation results from a zero-inflated Poisson (ZIP) model. This other model accounts for the prevalence of zero counts in the absenteeism data. The ZIP Poisson model also takes into account the fact that the determinants of zero counts could be different from the determinants of the number of days of absenteeism, due to job design or matching in the job market for example.

In all models, the dependent variable is the number of days of absence that are reported for the whole year. Note that the survey distinguishes between paid sick leave, unpaid leave and other paid leave ${ }^{12}$. Using days of absence in this type of survey might be problematic if the distribution of days of absence is not smooth. Moreover, it is possible that the respondent's ability to recall absences for a full year is not as good as we would like it to be ${ }^{13}$. For these reasons, in our empirical analysis, we also tested the model using weeks of absenteeism as the dependent variable. Since results did not differ, we show only results for days of absenteeism ${ }^{14}$.

Note that we were not able to estimate the full specification with parametrization (12) since the firm and employee random effects are not nested. Non-linear models with more than one variance component are very hard to estimate due to their high dimensionality, especially if the random effects are not nested, which is the case with firm and individual heterogeneity. Many methods have been

\footnotetext{
${ }^{12}$ Other paid leave does not include vacations, paternity/maternity leave or absence due to strikes or lock-out.

${ }^{13}$ Unfortunately, it is not possible to compare the number of absences as reported by the worker to administrative measures.

${ }^{14}$ The structure of the data also does not allow us to study episodes of absenteeism.
} 
proposed to overcome such numerical difficulties (see Lee and Nelder (1996) and Jiang (1998)) but unfortunately, it turns out that none are robust enough to deal with data sets of the size we use in this analysis. We compared results between two specifications, workplace or worker unobserved heterogeneity and since results did not differ much between the two specifications, we present results including worker heterogeneity only. Finally, in what follows, we focus mainly on coefficients and incidence rate ratios from the Poisson model but discuss results from the ZIP model when they differ.

Demographics and health We find that women are likely more likely to be absent. Women have 1.17 times the absence rate of men and this effect is even stronger if there are kids younger than six years old in the household ${ }^{15}$. Being married reduces absenteeism but the effect is significant at the $10 \%$ level only. Health is also found to be a very important determinant of the absenteeism decision. Individuals with no activity limitation have less than half the incidence rate of individuals with activity limitations. The impact of health is slightly less important in the ZIP model but also a statistically significant positive determinant of the probability of having no absenteeism which suggests that individuals with activity limitations will also be matched with jobs where absenteeism is permitted

Human capital Even with the detailed data we have on degrees obtained, we find almost no impact of schooling on absenteeism except for the category "University certificate above bachelor degree". The only two measures of human capital that are related to absenteeism decisions are seniority (positive but at a diminishing rate) and whether the individual received training in the past year (negative).

\footnotetext{
${ }^{15}$ Vistnes (1997) also finds a significant interaction between being a women and having young kids.
} 
Preference and job satisfaction We find very strong evidence that dissatisfaction with job contracts is related to absence. Workers who indicated that they would prefer to work more hours for more pay are less often absent and workers who would prefer to work less hours for less pay are more often absent. We think this is the strongest evidence yet that absenteeism decisions act as a mechanism to adjust hours to the worker's optimal schedule. Job satisfaction is also strongly related to absence. Workers who reported being very satisfied or satisfied with their job have 0.83 times the absence rate of dissatisfied individuals.

Income, wage and hours We find that, as predicted by our theoretical model, increasing income from other sources is related to more absence. The coefficient on wages is negative as predicted although the effect is not significant. We get a negative sign for contracted hours but the effect is very small. This could be due to the fact that a fair share of our sample does not work regular hours every week. Since we do not observe the contract, our measure of contracted hours is more a measure of the number of usual hours worked on average per week.

Work arrangement and technology use It has been said that new work arrangements lead to more stress and more absenteeism. Using detailed data about the scheduling of the work week, we find that workers who are able to do part of their work at home are less often absent and that workers who work on a reduced workweek are more often absent. Turning to technology, we find that workers using other technologies (such as cash registers, sales terminals, scanners, etc) have a higher incidence rate of absenteeism.

Organizational change Firms would normally be interested in finding what organizational practices succeed in reducing absenteeism when it is costly. 
We find that centralization and the introduction of flexible working hours in the firm are associated with higher absenteeism, while job rotation (or multi-skilling) and outsourcing are related to lower absenteeism ${ }^{16}$. It is interesting to contrast the impact of these organizational changes in the ZIP model. For example, the impact of outsourcing shows up only in the Poisson part of the ZIP model while the impact of centralization shows up only in the inflated part. This means that outsourcing is associated with reduced incidence of absenteeism while centralization is probably associated with reduction in "permitted" absenteeism in the job design.

Workplace practices We find no impact for flexible job design, suggestion programs, information sharing, the use of solving teams, labour-management committees and self-directed workgroups on absenteeism ${ }^{17}$. We do however find that workplaces that offer family support have more absences, but this effect works through the inflated part of the Poisson model which suggests it is also due to job design.

Cost of absenteeism We construct two measures of the indirect cost of absenteeism. We make the hypothesis that the worker is less likely to be penalized for his absence (through lower promotion probabilities) if vacancy rates are high and layoff rates are low. Although we find that our coefficients have the expected effects, neither are statistically significant.

Firm size, occupations, industry and time effects We find absenteeism to be greater in large firms and for all occupations compared to man-

\footnotetext{
${ }^{16}$ In separate work, we look at correlations between individual workplace practices in order to verify if some practices were most likely to be used in conjunction with others. Since no correlation is above 0.5 , we decide against using "bundles" of practices.

${ }^{17}$ Drago and Wooden (1992) find that workgroup cohesion is associated with lower levels of absence if job satisfaction is high and Wilson and Peel (1991) find that firms with participation schemes had significantly lower average absenteeism. These findings are not corroborated by our data.
} 
agers. Interestingly, we find no interindustry differentials in the incidence of absenteeism but the large majority of industry dummies ${ }^{18}$ are statistically significant in the inflated part of the ZIP model which suggests big industry differences in job design. Finally, all year dummies are negative. Since the reference year is 1999, we conclude that increases in absenteeism in that time period were probably due to changes in the workforce composition and job mix.

\section{Conclusion}

In this paper, we provide a careful examination of the factors associated with the absenteeism decision at the worker level using survey data where the information on the worker is linked to information about the workplace, something that has rarely been done. The data we use allow us to control for detailed demographic worker, job and firm characteristics. We find strong evidence that dissatisfaction with contracted hours is related to absence. We find that most human capital effects work through seniority and training. The predictions of our theoretical model are consistent with our results except for the coefficient on contracted hours which may be due to measurement error. We do not find strong indications that non traditional work arrangement lead to absenteeism. But the possibility of working at home is associated with lower absences. We find that firms that showed increased reliance on external suppliers (outsourcing) also saw absenteeism diminish.

Future work should be on devising estimation methods that would take into account the linked nature of the data. Such an estimation framework could be based on Monte Carlo Markov Chain methods to take into account the fact that the firm and worker effects are not nested. Also, it would be interesting to see if the determinants of absenteeism differ depending on the type of absenteeism

\footnotetext{
${ }^{18}$ The ommited category is natural ressources.
} 
(paid/unpaid, sick leave/other leave).

\section{References}

Abowd, J. M. and F. Kramarz (1999). The analysis of labor markets using matched employer-employee data. In O. Ashenfelter and D. Card (Eds.), Handbook of Labor Economics, vol 3B, Chapter 40, pp. 2629-2710. Elsevier Science North Holland.

Allen, S. G. (1981). An empirical model of work attendance. Review of Economics and Statistics 63(1), 77-87.

Allen, S. G. (1983). How much does absenteeism cost. Journal of Human Resources 18(3), 379-393.

Barmby, T. (2002). Worker absenteeism: a discrete hazard model with bivariate heterogeneity. Labour Economics 9, 469-476.

Barmby, T., C. Orme, and J. G. Treble (1991). Worker absenteeism: An analysis using microdata. Economic Journal 101(405), 214-229.

Blomquist, N. S. (1983). The effect of income taxation on the labor supply of married men in sweden. Journal of Public Economics 22(2), 169-197.

Delgado, M. A. and T. J. Kiesner (1997). Count data models with variance of unknown form: An application to a hedonic model of worker absenteeism. Review of Economics and Statistics 79(1), 41-49.

Dionne, G. and L. Eeckhoudt (1987). Proportional risk aversion, taxation and labour supply under uncertainty. Journal of Economics 47(4), 353-366.

Drago, R. and M. Wooden (1992). The determinants of labor absence: Economic factors and workgroup norms across countries. Industrial and Labor Relations Review 45(4), 764-778. 
Dunn, L. and S. A. Youngblood (1986). Absenteeism as a mechanism for approaching an optimal labor market equilibrium: An empirical study. Review of Economics and Statistics 68(4), 668-674.

Ehrenberg, R. G. (1970). Absenteeism and the overtime decision. American Economic Review 60(3), 352-357.

Frankel, E. (1921). Labor absenteeism. Journal of Political Economy 29(6), 487-499.

Gilleskie, D. B. (1998). A dynamic stochastic model of medical care use and work absence. Econometrica 66(1), 1-45.

Gouriéroux, C., A. Monfort, and A. Trognon (1984). Pseudo maximum likelihood functions: Applications to poisson models. Econometrica 52(3), $701-720$.

Hausman, J., B. Hall, and Z. Griliches (1984). Econometric models for count data with an application to the patents-r\&d relationship. Econometrica 52, 909-938.

Hausman, J. A. (1980). The effect of wages, taxes, and fixed costs on women's labor force participation. Journal of Public Economics 14(2), 161-194.

Henrekson, M. and M. Persson (2004). The effects on sick leave of changes in the sickness insurance system. Journal of Labor Economics 22, 87-113.

Jiang, J. (1998). Consistent estimators in generalized linear mixed models. Journal of the American Statistical Society 93(442), 720-729.

Johansson, P. and M. Palme (1996). Do economic incentives affect work absence? empirical evidence using Swedish micro data. Journal of Public Economics 59, 195-218.

Johansson, P. and M. Palme (2002). Assessing the effect of public policy on worker absenteeism. Journal of Human Resources 37, 381-409. 
Kauermann, G. and R. Ortlieb (2004). Temporal pattern in number of staff on sick leave: the effect of downsizing. Journal of the Royal Statistical Society Series C - Applied Statistics 53, 355-367.

Kenyon, P. and P. Dawkins (1989). A time series analysis of labour absence in australia. Review of Economics and Statistics 71(2), 232-239.

Lee, Y. and J. Nelder (1996). Hierarchical generalized linear models. Journal of the Royal Statistical Society B 58(4), 619-678.

Vistnes, J. P. (1997). Gender differences in days lost from work due to illness. Industrial and Labor Relations Review 50(2), 304-323.

Wilson, N. and M. J. Peel (1991). The impact on absenteeism and quits of profit-sharing and other forms of employee participation. Industrial and Labor Relations Review 44(3), 454-468. 


\section{A Comparative Statics of $t^{a}$}

\section{Decision with Respect to Different Parameters}

The first order condition with respect to $t^{a}$ is equal to:

$$
E\left[U_{L}-\left(w\left(1-s_{L}\right)+w^{a}\right) U_{C}\right]=0 .
$$

We write $H<0$ for the second order condition that is easily verified under risk aversion. We assume that leisure is not an inferior good.

So differentiating with respect to $R$ yields:

$$
\frac{d t^{a}}{d R}=-\frac{1}{H} E\left(U_{L C}-w^{t} U_{C C}\right)>0
$$

when $L$ is not an inferior good under certainty.

Now differentiating with respect to $w$ yields:

$$
\frac{d t^{a}}{d w}=\frac{1}{H} E U_{C}\left(1-s_{L}\right)-\frac{1}{H} E\left(U_{L C}-w^{t} U_{C C}\right)\left(t^{c}-\left(1-s_{L}\right) t^{a}\right)
$$

where

$$
w^{t} \equiv w\left(1-s_{L}\right)+w^{a}>0 .
$$

This can be rewritten as

$$
\frac{d t^{a}}{d w}=-\frac{1}{H} E\left[-\left(1-s_{L}\right) U_{C}+\left(U_{L C}-w^{t} U_{C C}\right)\left(t^{c}-\left(1-s_{L}\right) t^{a}\right)\right]
$$

which is negative under normal conditions of positive labor supply curve and when $s_{L}=0$ or small. When $s_{L}=1$, the effect is positive.

The sign of $d t^{a} / d t^{c}$ is given by the sign

$$
\frac{d t^{a}}{d t^{c}}=-\frac{1}{H} E\left[U_{L C}-w^{t} U_{C C}\right] w>0
$$


The sign of $d t^{a} / d E\left(w^{a}\right)$ is the same as that of $d t^{a} / d w^{a}$ under certainty.

$$
\frac{d t^{a}}{d E\left(w^{a}\right)}=-\frac{1}{H} E\left[-U_{C}-\left(U_{L C}-w^{t} U_{C C}\right) t^{a}\right]<0
$$

when $L$ is not an inferior good under certainty.

Finally, the sign of $d t^{a} / d($ Risk $)$ is that of

$$
\frac{d t^{a}}{d(\text { Risk })} \frac{1}{t^{a}}=U_{C C}\left(1-t^{a} I\right)+U_{C} t^{a} \frac{\partial I}{\partial w^{a}}<0
$$

where

$$
I \equiv \frac{U_{L C}-w^{t} U_{C C}}{U_{C}}>0
$$

if leisure is not an inferior good: $1-t^{a} I$ is positive when the supply curve of labor is positive and $\partial I / \partial w^{a}$ is non-increasing using an intuitive condition on the variation of proportional risk aversion along the budget line (see Dionne and Eeckhoudt (1987), for more details). 
B Tables 
Table 1: Summary statistics on absenteeism in Canada (1999)

\begin{tabular}{lrr}
\hline & \multicolumn{2}{c}{ Weeks absent } \\
\cline { 2 - 3 } & \multicolumn{1}{c}{ Freq. } & \multicolumn{1}{c}{$\%$} \\
\hline 0 & $9,717,342$ & 90.16 \\
1 & 669,090 & 6.21 \\
2 & 185,702 & 1.72 \\
3 & 25,927 & 0.24 \\
4 & 31,343 & 0.29 \\
5 & 7,437 & 0.07 \\
6 & 22,676 & 0.21 \\
7 & 14,159 & 0.13 \\
8 & 15,538 & 0.14 \\
9 & 10,675 & 0.10 \\
10 & 3,986 & 0.04 \\
& $(\ldots)$ & $(\ldots)$ \\
\hline \hline Total & $10,777,543$ & 100.00 \\
\hline \hline
\end{tabular}

Table 2: Summary statistics - Employees

\begin{tabular}{lrrrr}
\hline \hline & \multicolumn{2}{c}{1999} & \multicolumn{2}{c}{2001} \\
\cline { 2 - 5 } Dependent variable & Mean & Std.Dev. & Mean & Std.Dev. \\
\cline { 2 - 5 } Days of absence & 5.837 & 19.003 & 5.955 & 9.917 \\
Demographic characteristics & & & & \\
Women & 0.521 & 0.500 & 0.506 & 0.500 \\
Black & 0.011 & 0.104 & 0.014 & 0.119 \\
Other race & 0.280 & 0.449 & 0.309 & 0.462 \\
Language & 0.092 & 0.289 & 0.110 & 0.313 \\
Immigrant & 0.175 & 0.380 & 0.199 & 0.400 \\
Years since immigration & 3.988 & 10.181 & 4.361 & 10.594 \\
Married & 0.566 & 0.496 & 0.541 & 0.498 \\
Number of pre-school aged kids & 0.247 & 0.569 & 0.248 & 0.581 \\
Health & & & & \\
No activity limitation & 0.955 & 0.208 & 0.937 & 0.243 \\
\hline \hline
\end{tabular}


Table 2: Cont'd

Human Capital

High school degree

Industry certified training

Other training

Trade or vocational certificate

Some college

Complete college

Some university

Teacher's college

University certificate below bachelor degree

Bachelor degree

University certificate above bachelor degree

Master's degree

Degree in medicine or law

Earned doctorate

Seniority

Experience

Received training in the past year

\begin{tabular}{cccc}
\hline \multicolumn{2}{c}{1999} & \multicolumn{2}{c}{2001} \\
\hline Mean & Std.Dev. & Mean & Std.Dev. \\
\hline 0.107 & 0.309 & 0.120 & 0.325 \\
0.175 & 0.380 & 0.179 & 0.384 \\
0.020 & 0.141 & 0.011 & 0.104 \\
0.033 & 0.179 & 0.022 & 0.147 \\
0.088 & 0.283 & 0.098 & 0.297 \\
0.104 & 0.305 & 0.108 & 0.310 \\
0.181 & 0.385 & 0.188 & 0.391 \\
0.077 & 0.266 & 0.067 & 0.249 \\
0.002 & 0.049 & 0.001 & 0.030 \\
0.018 & 0.132 & 0.020 & 0.138 \\
0.130 & 0.337 & 0.133 & 0.339 \\
0.019 & 0.135 & 0.015 & 0.120 \\
0.031 & 0.174 & 0.028 & 0.165 \\
0.008 & 0.092 & 0.007 & 0.085 \\
0.006 & 0.078 & 0.005 & 0.067 \\
8.745 & 8.192 & 8.518 & 8.206 \\
16.167 & 10.714 & 16.411 & 10.993 \\
0.369 & 0.483 & 0.339 & 0.473 \\
\hline
\end{tabular}




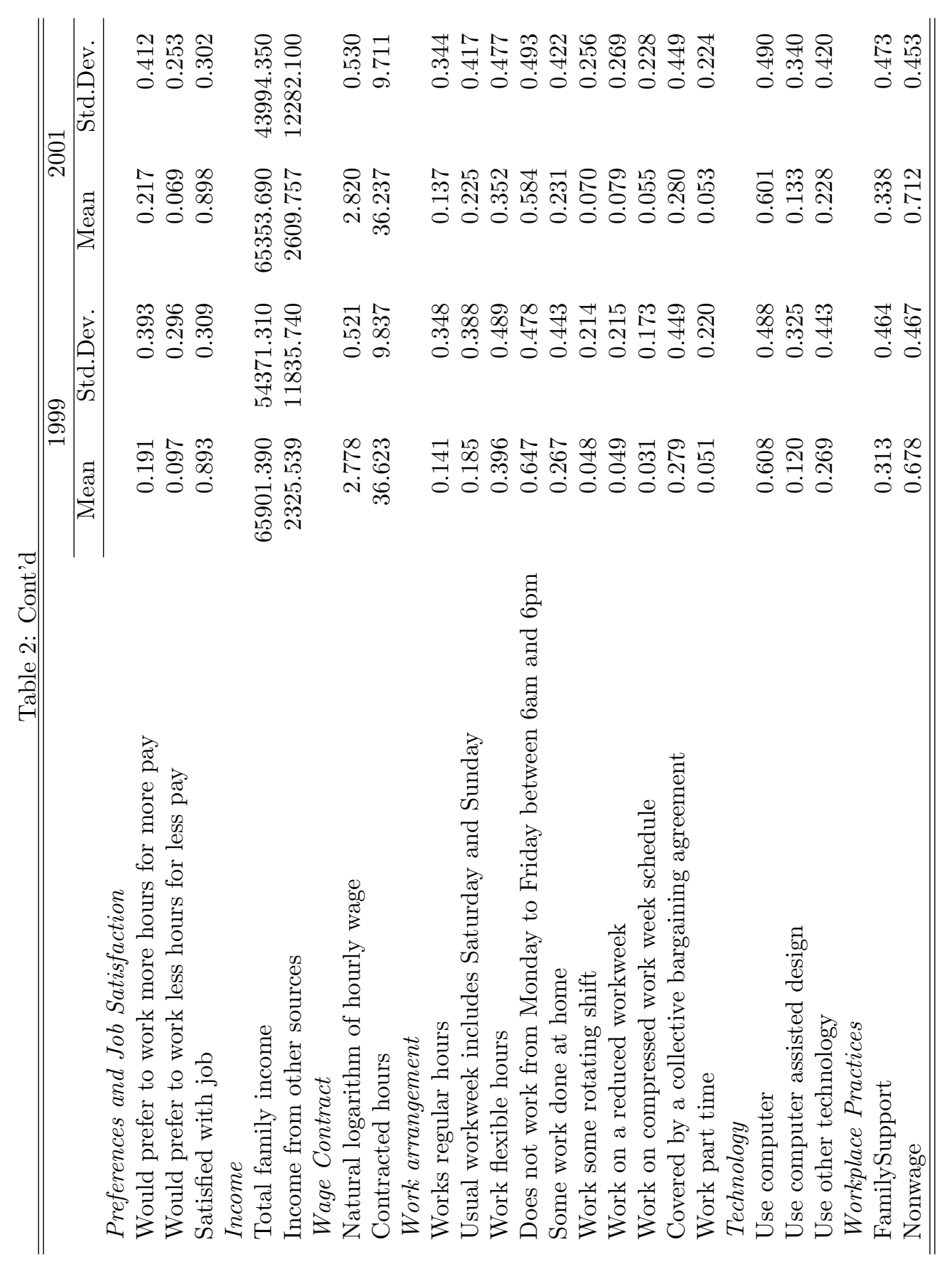


Table 2: Cont'd

\begin{tabular}{lcccc}
\hline \hline & \multicolumn{2}{c}{1999} & \multicolumn{2}{c}{2001} \\
\cline { 2 - 5 } Workplace Benefits & Mean & Std.Dev. & Mean & Std.Dev. \\
\cline { 2 - 5 } medic & 0.544 & 0.498 & 0.518 & 0.500 \\
life & 0.579 & 0.494 & 0.572 & 0.495 \\
dental & 0.532 & 0.499 & 0.553 & 0.497 \\
uispl & 0.330 & 0.470 & 0.312 & 0.463 \\
stock & 0.079 & 0.270 & 0.068 & 0.252 \\
empstck & 0.063 & 0.244 & 0.058 & 0.235 \\
Professions & & & & \\
manager & 0.151 & 0.358 & 0.112 & 0.315 \\
prof & 0.162 & 0.368 & 0.175 & 0.380 \\
tech & 0.390 & 0.488 & 0.414 & 0.493 \\
sale & 0.084 & 0.277 & 0.085 & 0.279 \\
office & 0.140 & 0.347 & 0.137 & 0.344 \\
othoccup & 0.074 & 0.262 & 0.077 & 0.267 \\
\hline \hline Number of observations & \multicolumn{2}{c}{23540} & \multicolumn{3}{c}{20377} \\
\hline
\end{tabular}


Table 3: Summary statistics - Employers

\begin{tabular}{|c|c|c|}
\hline \multirow{3}{*}{ Changes in organisational practices } & \multicolumn{2}{|c|}{1999} \\
\hline & Mean & Std.Dev. \\
\hline & & \\
\hline Integration & 0.247 & 0.431 \\
\hline Centralization & 0.127 & 0.333 \\
\hline Downsizing & 0.131 & 0.338 \\
\hline Decentralization & 0.075 & 0.264 \\
\hline Temporary & 0.064 & 0.245 \\
\hline Use part-time & 0.126 & 0.332 \\
\hline Re-engineering & 0.335 & 0.472 \\
\hline Use overtime & 0.133 & 0.340 \\
\hline Adopted flexible time & 0.201 & 0.401 \\
\hline Destratification & 0.069 & 0.254 \\
\hline Rotation & 0.253 & 0.435 \\
\hline TQM & 0.205 & 0.404 \\
\hline Outsourcing & 0.158 & 0.364 \\
\hline Collaboration & 0.186 & 0.389 \\
\hline Other changes & 0.009 & 0.095 \\
\hline Workplace Practices & & \\
\hline Suggestion program & 0.303 & 0.460 \\
\hline Flexible job hours & 0.308 & 0.462 \\
\hline Information sharing & 0.496 & 0.500 \\
\hline Teams & 0.256 & 0.437 \\
\hline Committee & 0.197 & 0.398 \\
\hline Workgroups & 0.103 & 0.305 \\
\hline Cost of absenteeism & & \\
\hline Vacancy rate & 0.026 & 0.062 \\
\hline Layoff rate & 0.101 & 0.374 \\
\hline
\end{tabular}


Table 3: Cont'd

\begin{tabular}{lcc}
\hline \hline & \multicolumn{2}{c}{1999} \\
\cline { 2 - 3 } Size & Mean & Std.Dev. \\
\cline { 2 - 3 } 10-19 employees & 0.461 & 0.499 \\
20-99 employees & 0.460 & 0.498 \\
100-499 employees & 0.070 & 0.255 \\
500 employees and more & 0.010 & 0.098 \\
Industry & \\
Natural resources & 0.015 & 0.120 \\
Primary product manufacturing & 0.025 & 0.156 \\
Secondary product manufacturing & 0.030 & 0.170 \\
Labour intensive tertiary manufacturing & 0.045 & 0.208 \\
Capital intensive tertiary manufacturing & 0.048 & 0.214 \\
Construction & 0.053 & 0.223 \\
Transportation & 0.134 & 0.340 \\
Communication and other utilities & 0.022 & 0.146 \\
Retail trade and consumer service & 0.302 & 0.459 \\
Finance and insurance & 0.069 & 0.253 \\
Real estate & 0.014 & 0.117 \\
Business services & 0.110 & 0.313 \\
Education and health services & 0.103 & 0.304 \\
Information and cultural industries & 0.031 & 0.174 \\
\hline \hline N = 4072 &
\end{tabular}


Table 4: Poisson regressions on days of absenteeism

\begin{tabular}{|c|c|c|c|c|}
\hline \multirow{3}{*}{ Demographic characteristics } & \multicolumn{2}{|c|}{ Poisson Model } & \multicolumn{2}{|c|}{ RE ZIP Poisson } \\
\hline & Coef. & \multirow[t]{2}{*}{ IRR } & \multirow[t]{2}{*}{ Poisson } & \multirow[t]{2}{*}{ Inflate } \\
\hline & & & & \\
\hline \multirow[t]{2}{*}{ Women } & $0.161^{* *}$ & $1.174^{* *}$ & 0.075 & $-0.244^{* * *}$ \\
\hline & $(0.065)$ & $(0.076)$ & $(0.060)$ & $(0.064)$ \\
\hline \multirow[t]{2}{*}{ Black } & -0.100 & 0.905 & -0.061 & 0.070 \\
\hline & $(0.152)$ & $(0.138)$ & $(0.135)$ & $(0.168)$ \\
\hline \multirow[t]{2}{*}{ Other race } & -0.051 & 0.950 & -0.001 & $0.146^{* * *}$ \\
\hline & $(0.060)$ & $(0.057)$ & $(0.056)$ & $(0.057)$ \\
\hline \multirow[t]{2}{*}{ Language at work differs from the one at home } & 0.045 & 1.046 & 0.011 & -0.095 \\
\hline & $(0.067)$ & $(0.070)$ & $(0.063)$ & $(0.079)$ \\
\hline \multirow[t]{2}{*}{ Immigrant } & -0.134 & 0.875 & -0.095 & 0.109 \\
\hline & $(0.141)$ & $(0.124)$ & $(0.130)$ & $(0.127)$ \\
\hline \multirow[t]{2}{*}{ Years since immigration } & 0.004 & 1.004 & 0.004 & 0.000 \\
\hline & $(0.006)$ & $(0.006)$ & $(0.005)$ & $(0.005)$ \\
\hline \multirow[t]{2}{*}{ Married } & $-0.092^{*}$ & $0.912^{*}$ & -0.067 & $0.087^{*}$ \\
\hline & $(0.049)$ & $(0.044)$ & $(0.047)$ & $(0.051)$ \\
\hline \multirow[t]{2}{*}{ Number of pre-school aged kids } & $-0.160 * * *$ & $0.852^{* * *}$ & $-0.127^{* * *}$ & 0.089 \\
\hline & $(0.057)$ & $(0.048)$ & $(0.046)$ & $(0.067)$ \\
\hline \multirow[t]{2}{*}{ Women $*$ pre-school aged kids } & $0.248^{* * *}$ & $1.282^{* * *}$ & $0.221^{* * *}$ & -0.108 \\
\hline & $(0.078)$ & $(0.100)$ & $(0.070)$ & $(0.093)$ \\
\hline \multicolumn{5}{|l|}{ Health } \\
\hline \multirow[t]{2}{*}{ No activity limitation } & $-0.857^{* * *}$ & $0.424^{* * *}$ & $-0.711^{* * *}$ & $0.460^{* * *}$ \\
\hline & $(0.067)$ & $(0.029)$ & & $(0.080)$ \\
\hline
\end{tabular}

Statistical significance: ${ }^{*}=10 \% ;{ }^{* *}=5 \% ; * * *=1 \%$.

Robust standard error in parantheses 


\section{Table 4: Cont'd}

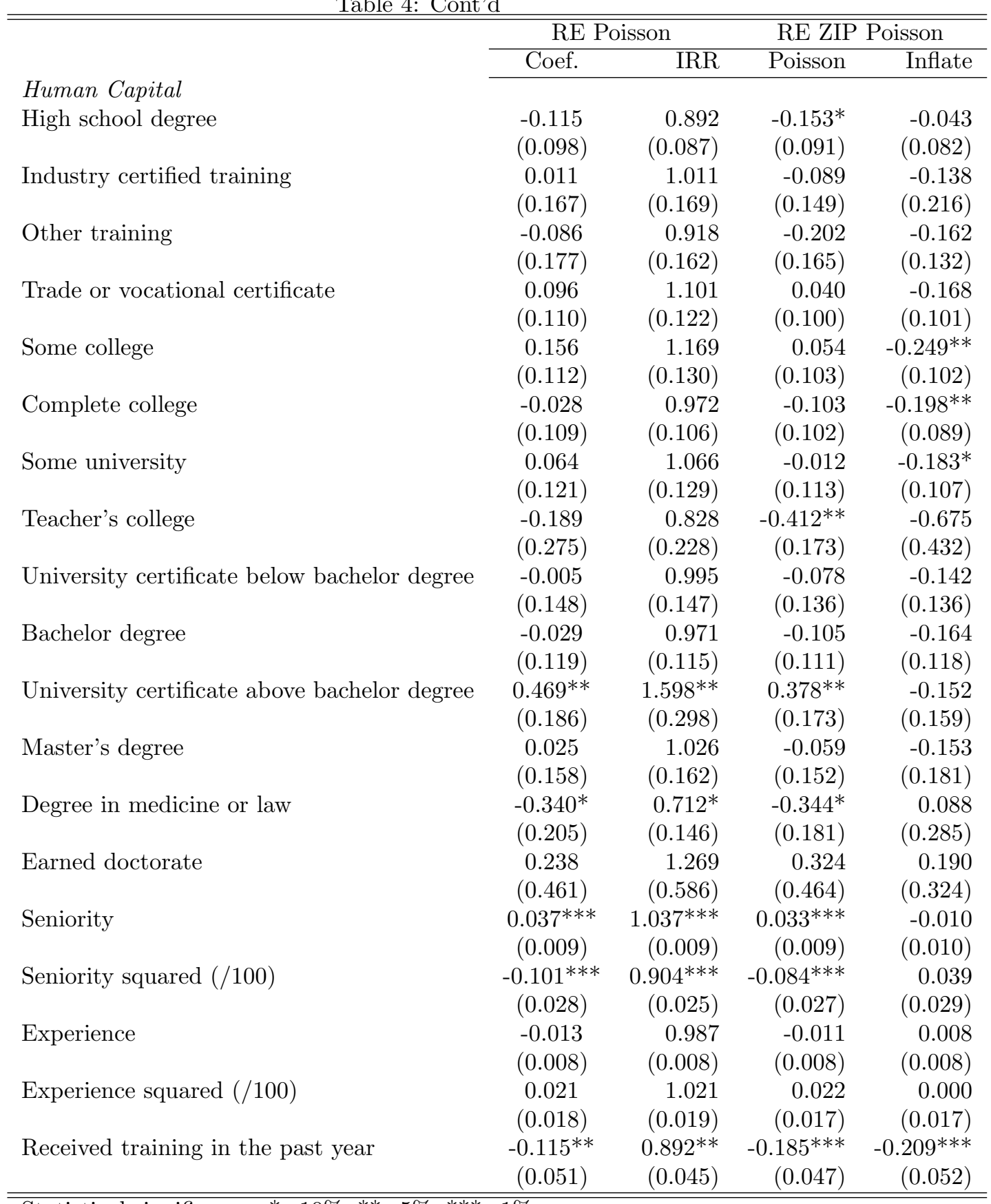

Statistical significance: ${ }^{*}=10 \% ;{ }^{* *}=5 \% ; * * *=1 \%$.

Robust standard error in parantheses 
Table 4: Cont'd

\begin{tabular}{|c|c|c|c|c|}
\hline & \multicolumn{2}{|c|}{ RE Poisson } & \multicolumn{2}{|c|}{ RE ZIP Poisson } \\
\hline & Coef. & IRR & Poisson & Inflate \\
\hline \multicolumn{5}{|l|}{ Preferences and Job Satisfaction } \\
\hline \multirow[t]{2}{*}{ Would prefer to work more hours for more pay } & $-0.119^{*}$ & $0.888^{*}$ & $-0.151^{* *}$ & -0.053 \\
\hline & $(0.069)$ & $(0.061)$ & $(0.065)$ & $(0.058)$ \\
\hline \multirow[t]{2}{*}{ Would prefer to work less hours for less pay } & $0.258 * * *$ & $1.294^{* * *}$ & $0.160^{* *}$ & $-0.265^{* * *}$ \\
\hline & $(0.066)$ & $(0.085)$ & $(0.064)$ & $(0.079)$ \\
\hline \multirow[t]{2}{*}{ Satisfied with job } & $-0.192^{* * *}$ & $0.825^{* * *}$ & $-0.130^{*}$ & $0.154^{* * *}$ \\
\hline & $(0.072)$ & $(0.059)$ & $(0.067)$ & $(0.067)$ \\
\hline \multicolumn{5}{|l|}{ Income } \\
\hline \multirow[t]{2}{*}{ Total family income (000s) } & -0.000 & 1.000 & -0.000 & 0.000 \\
\hline & $(0.001)$ & $(0.001)$ & $(0.001)$ & $(0.001)$ \\
\hline \multirow[t]{2}{*}{ Income from other sources (000s) } & $0.002^{* * *}$ & $1.002^{* * *}$ & $0.002^{* * *}$ & -0.003 \\
\hline & $(0.001)$ & $(0.001)$ & $(0.001)$ & $(0.002)$ \\
\hline \multicolumn{5}{|l|}{ Wage Contract } \\
\hline \multirow[t]{2}{*}{ Natural logarithm of hourly wage } & -0.103 & 0.902 & -0.086 & 0.110 \\
\hline & $(0.074)$ & $(0.066)$ & $(0.070)$ & $(0.074)$ \\
\hline \multirow[t]{2}{*}{ Contracted hours } & -0.005 & 0.995 & $-0.010^{* *}$ & -0.006 \\
\hline & $(0.004)$ & $(0.004)$ & $(0.005)$ & $(0.003)$ \\
\hline \multicolumn{5}{|l|}{ Work arrangement } \\
\hline \multirow[t]{2}{*}{ Works regular hours } & 0.052 & 1.053 & $0.195^{* *}$ & $0.335^{* * *}$ \\
\hline & $(0.086)$ & $(0.091)$ & $(0.078)$ & $(0.068)$ \\
\hline \multirow[t]{2}{*}{ Usual workweek includes Saturday and Sunday } & -0.028 & 0.972 & 0.015 & 0.099 \\
\hline & $(0.081)$ & $(0.078)$ & $(0.076)$ & $(0.080)$ \\
\hline \multirow[t]{2}{*}{ Work flexible hours } & 0.010 & 1.010 & 0.035 & 0.074 \\
\hline & $(0.053)$ & $(0.053)$ & $(0.050)$ & $(0.047)$ \\
\hline \multirow[t]{2}{*}{ Does not work from MtoF between 6 am and $6 \mathrm{pm}$} & -0.037 & 0.964 & -0.086 & $-0.221^{* * *}$ \\
\hline & $(0.072)$ & $(0.070)$ & $(0.068)$ & $(0.066)$ \\
\hline \multirow[t]{2}{*}{ Some work done at home } & $-0.122^{*}$ & $0.885^{*}$ & -0.070 & $0.126^{*}$ \\
\hline & $(0.074)$ & $(0.065)$ & $(0.071)$ & $(0.065)$ \\
\hline \multirow[t]{2}{*}{ Work some rotating shift } & 0.021 & 1.022 & -0.034 & -0.138 \\
\hline & $(0.096)$ & $(0.098)$ & $(0.091)$ & $(0.085)$ \\
\hline \multirow[t]{2}{*}{ Work on a reduced workweek } & $0.270^{* *}$ & $1.310^{* *}$ & $0.252^{* *}$ & -0.059 \\
\hline & $(0.107)$ & $(0.141)$ & $(0.101)$ & $(0.100)$ \\
\hline \multirow[t]{2}{*}{ Work on compressed work week schedule } & 0.012 & 1.012 & 0.044 & 0.034 \\
\hline & $(0.093)$ & $(0.094)$ & $(0.085)$ & $(0.091)$ \\
\hline \multirow[t]{2}{*}{ Covered by a collective bargaining agreement } & $0.278^{* * *}$ & $1.320 * * *$ & $0.193^{* * *}$ & $-0.238 * * *$ \\
\hline & $(0.058)$ & $(0.076)$ & $(0.056)$ & $(0.057)$ \\
\hline \multicolumn{5}{|l|}{ Technology } \\
\hline Use computer & -0.081 & 0.922 & -0.112 & -0.054 \\
\hline & $(0.075)$ & $(0.069)$ & $(0.069)$ & $(0.058)$ \\
\hline Use computer assisted design & 0.084 & 1.088 & 0.054 & $-0.108^{* *}$ \\
\hline & $(0.061)$ & $(0.066)$ & $(0.059)$ & $(0.056)$ \\
\hline Use other technology & $0.134^{* * *}$ & $1.143^{* * *}$ & 0.075 & $-0.157 * * *$ \\
\hline & $(0.052)$ & $(0.059)$ & $(0.049)$ & $(0.054)$ \\
\hline
\end{tabular}

Statistical significance: ${ }^{*}=10 \% ;{ }^{* *}=5 \% ;{ }^{* * *}=1 \%$.

Robust standard error in parantheses 31 
Table 4: Cont'd

\begin{tabular}{|c|c|c|c|c|}
\hline & \multicolumn{2}{|c|}{ RE Poisson } & \multicolumn{2}{|c|}{ "RE ZIP Poisson } \\
\hline & Coef. & IRR & Poisson & Inflate \\
\hline \multicolumn{5}{|c|}{ Changes in organisational practices } \\
\hline \multirow[t]{2}{*}{ Integration } & -0.064 & 0.938 & -0.066 & -0.041 \\
\hline & $(0.055)$ & $(0.052)$ & $(0.052)$ & $(0.063)$ \\
\hline \multirow[t]{2}{*}{ Centralization } & $0.121^{*}$ & $1.128^{*}$ & 0.068 & $-0.182^{* * *}$ \\
\hline & $(0.062)$ & $(0.070)$ & $(0.059)$ & $(0.057)$ \\
\hline \multirow[t]{2}{*}{ Downsizing } & -0.018 & 0.982 & -0.009 & 0.020 \\
\hline & $(0.050)$ & $(0.050)$ & $(0.048)$ & $(0.052)$ \\
\hline \multirow{2}{*}{ Decentralization } & 0.007 & 1.007 & 0.009 & 0.013 \\
\hline & $(0.076)$ & $(0.076)$ & $(0.072)$ & $(0.079)$ \\
\hline \multirow[t]{2}{*}{ Temporary } & 0.007 & 1.007 & -0.022 & $-0.147^{* *}$ \\
\hline & $(0.065)$ & $(0.065)$ & $(0.063)$ & $(0.069)$ \\
\hline \multirow{2}{*}{ Use part-time } & 0.011 & 1.011 & 0.017 & 0.049 \\
\hline & $(0.066)$ & $(0.067)$ & $(0.064)$ & $(0.066)$ \\
\hline \multirow{2}{*}{ Re-engineering } & 0.039 & 1.040 & 0.058 & 0.075 \\
\hline & $(0.060)$ & $(0.062)$ & $(0.057)$ & $(0.057)$ \\
\hline \multirow{2}{*}{ Use overtime } & -0.059 & 0.943 & -0.050 & 0.081 \\
\hline & $(0.060)$ & $(0.057)$ & $(0.058)$ & $(0.069)$ \\
\hline \multirow[t]{2}{*}{ Adopted flexible time } & $0.185^{* * *}$ & $1.203^{* * *}$ & $0.173^{* * *}$ & -0.069 \\
\hline & $(0.063)$ & $(0.075)$ & $(0.059)$ & $(0.061)$ \\
\hline \multirow{2}{*}{ Destratification } & 0.094 & 1.098 & 0.093 & 0.052 \\
\hline & $(0.063)$ & $(0.069)$ & $(0.060)$ & $(0.065)$ \\
\hline \multirow[t]{2}{*}{ Rotation } & $-0.171^{* * *}$ & $0.843^{* * *}$ & $-0.093^{*}$ & $0.164^{* * *}$ \\
\hline & $(0.053)$ & $(0.045)$ & $(0.051)$ & $(0.057)$ \\
\hline \multirow[t]{2}{*}{ TQM } & 0.000 & 1.000 & -0.038 & $-0.103^{*}$ \\
\hline & $(0.052)$ & $(0.052)$ & $(0.050)$ & $(0.055)$ \\
\hline \multirow[t]{2}{*}{ Outsourcing } & $-0.120^{* *}$ & $0.887^{* *}$ & $-0.112^{* *}$ & 0.009 \\
\hline & $(0.056)$ & $(0.050)$ & $(0.053)$ & $(0.064)$ \\
\hline \multirow[t]{2}{*}{ Collaboration } & -0.024 & 0.976 & -0.046 & -0.021 \\
\hline & $(0.056)$ & $(0.054)$ & $(0.053)$ & $(0.057)$ \\
\hline \multirow[t]{2}{*}{ Other changes } & 0.029 & 1.029 & 0.064 & 0.112 \\
\hline & $(0.186)$ & $(0.191)$ & $(0.175)$ & $(0.108)$ \\
\hline
\end{tabular}

Statistical significance: ${ }^{*}=10 \% ;{ }^{*}=5 \% ; * * *=1 \%$.

Robust standard error in parantheses 


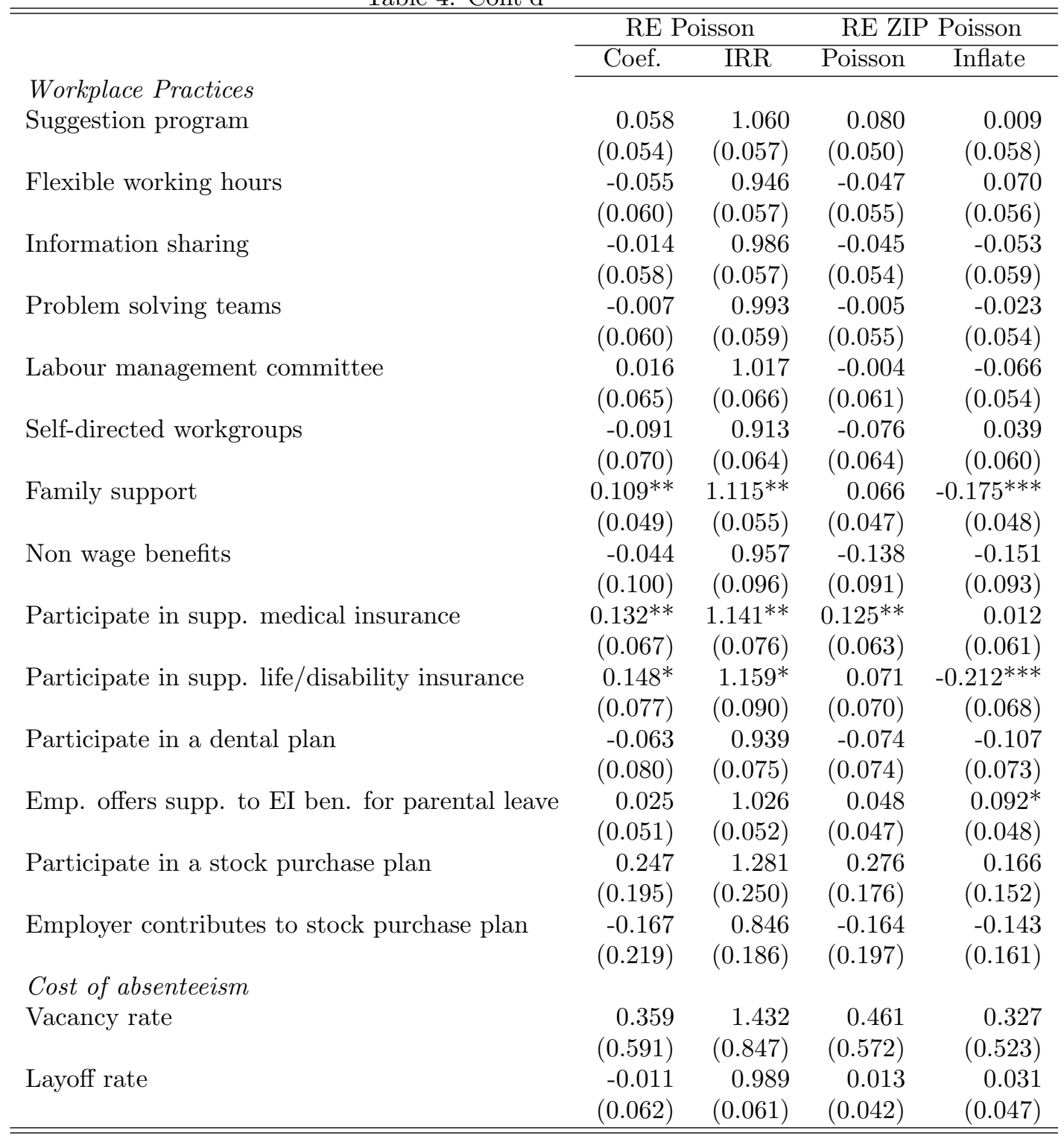

Statistical significance: ${ }^{*}=10 \% ;{ }^{* *}=5 \% ; * * *=1 \%$.

Robust standard error in parantheses 
Table 4: Cont'd

\begin{tabular}{|c|c|c|c|c|}
\hline & \multicolumn{2}{|c|}{ RE Poisson } & \multicolumn{2}{|c|}{ RE ZIP Poisson } \\
\hline & Coef. & IRR & Poisson & Inflate \\
\hline \multicolumn{5}{|l|}{ Firm Size } \\
\hline \multirow[t]{2}{*}{ 20-99 employees } & $0.142^{*}$ & $1.152^{*}$ & $0.131^{*}$ & 0.013 \\
\hline & $(0.080)$ & $(0.093)$ & $(0.073)$ & $(0.094)$ \\
\hline \multirow[t]{2}{*}{ 100-499 employees } & $0.276^{* * *}$ & $1.317^{* *}$ & $0.240^{* * *}$ & -0.076 \\
\hline & $(0.088)$ & $(0.115)$ & $(0.081)$ & $(0.097)$ \\
\hline \multirow[t]{2}{*}{500 employees and more } & $0.171^{*}$ & $1.187^{*}$ & $0.163^{*}$ & -0.034 \\
\hline & $(0.094)$ & $(0.111)$ & $(0.086)$ & $(0.109)$ \\
\hline \multicolumn{5}{|l|}{ Occupation } \\
\hline \multirow[t]{2}{*}{ Professional } & $0.212^{* *}$ & $1.237^{* *}$ & 0.128 & $-0.178^{*}$ \\
\hline & $(0.102)$ & $(0.126)$ & $(0.092)$ & $(0.100)$ \\
\hline \multirow[t]{2}{*}{ Technician/Trades } & $0.270^{* * *}$ & $1.310^{* * *}$ & $0.187^{* *}$ & -0.130 \\
\hline & $(0.103)$ & $(0.135)$ & $(0.093)$ & $(0.088)$ \\
\hline \multirow[t]{2}{*}{ Sales/Marketing } & 0.127 & 1.135 & -0.016 & -0.183 \\
\hline & $(0.144)$ & $(0.164)$ & $(0.132)$ & $(0.143)$ \\
\hline \multirow[t]{2}{*}{ Clerical/Administrative } & 0.157 & 1.170 & 0.032 & $-0.279^{* * *}$ \\
\hline & $(0.114)$ & $(0.133)$ & $(0.102)$ & $(0.101)$ \\
\hline \multirow[t]{2}{*}{ Other } & $0.297^{*}$ & $1.346^{*}$ & $0.233^{*}$ & -0.065 \\
\hline & $(0.153)$ & $(0.206)$ & $(0.140)$ & $(0.121)$ \\
\hline
\end{tabular}

Statistical significance: $*=10 \% ; * *=5 \% ; * * *=1 \%$.

Robust standard error in parantheses 
Table 4: Cont'd

\begin{tabular}{|c|c|c|c|c|}
\hline & \multicolumn{2}{|c|}{ RE Poisson } & \multicolumn{2}{|c|}{ RE ZIP Poisson } \\
\hline & Coef. & IRR & Poisson & Inflate \\
\hline \multicolumn{5}{|l|}{ Industry } \\
\hline \multirow{2}{*}{ Primary product manuf. } & -0.006 & 0.994 & -0.097 & $-0.181^{*}$ \\
\hline & $(0.163)$ & $(0.162)$ & $(0.153)$ & $(0.106)$ \\
\hline \multirow{2}{*}{ Secondary product manuf. } & -0.059 & 0.943 & -0.210 & $-0.280 * * *$ \\
\hline & $(0.172)$ & $(0.162)$ & $(0.163)$ & $(0.110)$ \\
\hline \multirow{2}{*}{ Labour intensive tertiary manufac. } & -0.119 & 0.888 & $-0.255^{*}$ & $-0.294^{* * *}$ \\
\hline & $(0.159)$ & $(0.141)$ & $(0.147)$ & $(0.114)$ \\
\hline \multirow[t]{2}{*}{ Capital intensive tertiary manufac. } & -0.101 & 0.904 & -0.233 & $-0.265^{* *}$ \\
\hline & $(0.158)$ & $(0.143)$ & $(0.146)$ & $(0.108)$ \\
\hline \multirow[t]{2}{*}{ Construction } & 0.117 & 1.125 & 0.072 & -0.057 \\
\hline & $(0.178)$ & $(0.200)$ & $(0.165)$ & $(0.134)$ \\
\hline \multirow[t]{2}{*}{ Transportation } & -0.060 & 0.942 & -0.180 & $-0.273^{* * *}$ \\
\hline & $(0.158)$ & $(0.149)$ & $(0.147)$ & $(0.110)$ \\
\hline \multirow[t]{2}{*}{ Communication and other utilities } & 0.086 & 1.089 & -0.123 & $-0.486^{* * *}$ \\
\hline & $(0.176)$ & $(0.192)$ & $(0.166)$ & $(0.120)$ \\
\hline \multirow[t]{2}{*}{ Retail trade } & -0.035 & 0.966 & -0.194 & $-0.343^{* * *}$ \\
\hline & $(0.162)$ & $(0.156)$ & $(0.151)$ & $(0.120)$ \\
\hline \multirow[t]{2}{*}{ Finance and insurance } & 0.093 & 1.098 & -0.184 & $-0.691 * * *$ \\
\hline & $(0.161)$ & $(0.177)$ & $(0.148)$ & $(0.135)$ \\
\hline \multirow[t]{2}{*}{ Real estate } & $-0.311^{*}$ & $0.733^{*}$ & $-0.538^{* * *}$ & $-0.507^{* *}$ \\
\hline & $(0.178)$ & $(0.130)$ & $(0.159)$ & $(0.215)$ \\
\hline \multirow[t]{2}{*}{ Business services } & -0.008 & 0.992 & $-0.245^{*}$ & $-0.541^{* * *}$ \\
\hline & $(0.160)$ & $(0.159)$ & $(0.148)$ & $(0.117)$ \\
\hline \multirow{2}{*}{ Education and health services } & 0.228 & 1.257 & -0.045 & $-0.673^{* * *}$ \\
\hline & $(0.156)$ & $(0.196)$ & $(0.144)$ & $(0.113)$ \\
\hline \multirow[t]{2}{*}{ Information and cultural industries } & -0.021 & 0.979 & -0.272 & $-0.550 * * *$ \\
\hline & $(0.189)$ & $(0.185)$ & $(0.180)$ & $(0.125)$ \\
\hline \multicolumn{5}{|l|}{ Year Dummies } \\
\hline \multirow[t]{2}{*}{ Year $=2000$} & 0.011 & 1.011 & $-0.104^{*}$ & $-0.340^{* * *}$ \\
\hline & $(0.065)$ & $(0.066)$ & $(0.061)$ & $(0.049)$ \\
\hline \multirow[t]{2}{*}{ Year $=2001$} & -0.057 & 0.944 & $-0.168^{* * *}$ & $-0.339 * * *$ \\
\hline & $(0.066)$ & $(0.062)$ & $(0.061)$ & $(0.060)$ \\
\hline \multirow[t]{2}{*}{ Year $=2002$} & -0.101 & 0.904 & $-0.211^{* * *}$ & $-0.305^{* * *}$ \\
\hline & $(0.068)$ & $(0.062)$ & $(0.064)$ & $(0.064)$ \\
\hline \multirow[t]{2}{*}{ Constant } & $2.557^{* * *}$ & & $3.696^{* * *}$ & $0.522^{*}$ \\
\hline & $(0.406)$ & & $(0.388)$ & $(0.285)$ \\
\hline Observations & 63539 & & & \\
\hline
\end{tabular}

Statistical significance: ${ }^{*}=10 \% ;{ }^{* *}=5 \% ; * * *=1 \%$.

Robust standard error in parantheses 


\section{Liste des cahiers de recherche publiés par les professeurs des H.E.C. 2004-2005}

\section{Institut d'économie appliquée}

IEA-04-01: LEACH, ANDREW. «Integrated Assessment of Climate Change Using an OLG Model », 34 pages.

IEA-04-02: LEACH, ANDREW. " SubGame, set and match. Identifying Incentive Response in a Tournament », 39 pages.

IEA-04-03: LEACH, ANDREW. « The Climate Change Learning Curve », 27 pages.

IEA-04-04: DOSTIE, BENOIT; VENCATACHELLUM, DÉSIRÉ. « Compulsory and Voluntary Remittances: Evidence from Child Domestic Workers in Tunisia », 46 pages.

IEA-04-05: RENGIFo, E.W.; ROMBOUTS, J.V.K. « Dynamic Optimal Portfolio in a VaR Framework », 33 pages.

IEA-04-06: DOSTIE, BENOIT; TRÉPANIER, MATHIEU. « Return to Computer Use and Organizational Practices of the Firm », 41 pages.

IEA-04-07: ALLARD, MARIE; LÉGER, PIERRE THOMAS; ROCHAIX, LISE. « Provider Competition in a Dynamic Setting » 32 pages

IEA-04-08: MAURICE N. MARCHON. «Perspectives économiques canadiennes dans un contexte international » 27 pages.

IEA-04-09: NORMANDIN, MICHEL. " The Current Account and the Interest Differential in Canada », 27 pages.

IEA-04-10 AZAM, JEAN-PAUL; GAUTHIER, BERNARD; GOYETTE, JONATHAN. « The Effect of Fiscal Policy and Corruption Control Mechanisms on Firm Growth and Social Welfare: Theory and Evidence », 50 pages.

IEA-04-11 RUTH DUPRÉ. «The Prohibition of Alcohol Revisited : the US Case in International Perspective », 28 pages.

IEA-04-12 BÉlAIR, MARJOLAINE; GAUTHIER, BERNARD. «Les effets de l'immigration sur le commerce bilatéral : le cas de l’Australie et des pays de l’Asie du Sud-Est », 50 pages. 
IEA-04-13 LAROCQUe, DENIS; NORMANDIN, MICHEL. «Econometric Inference, Cyclical Fluctuations, and Superior Information », 40 pages.

IEA-04-14 ROMBOUTS, JEROEN V.K.; VERBEEK MARNO. « Evaluating Portfolio Value-at-Risk Using Semi-parametric Garch Models », 30 pages.

IEA-05-01 DÉSIRÉ VENCATACHALLUM ET BRUNO VERSAEVEL. « R\&D Delegation in a Duopoly with Spillovers », 57 pages.

IEA-05-02 MiCHEL NORMANDin ET PASCAL St-AMOUR.. « An Empirical Analysis of U.S. Aggregate Portfolio Allocations », 33 pages.

IEA-05-03 MARTIN BOILEAU ET MiCHEL NORMANDIN. « Closing International Real Business Cycle Models with Restricted Financial Markets », 36 pages. 